\title{
Influence of $n$-Paraffin Composition on the Aging of Wax-Oil Gel Deposits
}

\author{
K. G. Paso and H. Scott Fogler \\ Dept. of Chemical Engineering, University of Michigan, Ann Arbor, MI 48109
}

\begin{abstract}
An excess Gibbs free energy model is applied to investigate the influence of n-paraffin composition on the aging behavior of wax-oil gel deposits known to form in subsea petroleum transport pipelines. The aging of wax-oil gels occurs by a counterdiffusion process where wax molecules with carbon numbers greater than a critical carbon number (CCN) diffuse into the gel matrix, and vice versa. Model crude oils were formulated to exhibit varying decreasing exponential distributions of n-paraffin components in the range $n-C_{9}$ to $n-C_{53}$. Deposition experiments were conducted using a laboratory cold finger apparatus simulating the cold wall of a subsea pipeline. Gas chromatography analysis of gel deposit compositions yielded experimental CCN values. A solid-liquidphase equilibrium model, employing a modified version of UNIQUAC to compute solid-phase component activity coefficients, was able to successfully predict the critical carbon number for a variety of model oil n-paraffin compositions.
\end{abstract}

\section{Introduction}

The presence of naturally occurring long-chain saturated aliphatic hydrocarbons in crude oil can cause wax precipitation and deposition problems in petroleum transport pipelines and processing equipment. According to the U.S. DOE (2001), remediating subsea pipeline blockages caused by wax deposition can cost $\$ 1$ million per mile. Incipient wax-oil gel deposits contain a significant fraction of occluded oil within a solid crystalline wax matrix (Singh et al., 1999). In-pipe temperature gradients cause the deposits to age, whereby the wax content increases with time (Singh et al., 2000). The aging process causes paraffin deposits to harden and become difficult to remove by conventional mechanical methods. The mechanism of aging has been demonstrated to be due to continuous diffusion of long-chain $n$-paraffin molecules from the bulk oil into the gel matrix (Singh et al., 2000). A secondary mechanism thought to be responsible for the hardening of paraffin deposits is Ostwald ripening. Coutinho et al. (2003) have demonstrated that this phenomenon, whereby smaller paraffin crystals recrystallize, leads to an increase in the average crystal size and rheological strength of a wax-oil gel. In the present work the term "aging" refers exclusively to the increase in wax content of wax-oil gel deposits.

Crude oil consists of a complex mixture of hydrocarbon components including saturates, aromatics, resins, and as-

Correspondence concerning this article should be addressed to H. S. Fogler. phaltenes. Waxes derived from crude oil are typically classified as either macrocrystalline or microcrystalline waxes. Macrocrystalline waxes consist of primarily straight-chain paraffin components, while microcrystalline waxes also contain a high proportion of branched and cyclic hydrocarbons (Hansen et al., 1991). Wax deposits recovered from crude oil pipelines have been found to be enriched in $n$-paraffin components (Roehner et al., 2002). It has been demonstrated that continuous distributions of $C_{19^{+}} n$-paraffin components form a single orthorhombic solid solution, where the molecular packing identity period along the long c-axis is quasi-equal to the average length of the $n$-paraffin molecules in the solid phase (Dirand et al., 1998).

\section{Wax Deposition Phenomena}

When a waxy crude oil comes into contact with a cold $\left(\sim 4^{\circ} \mathrm{C}\right)$ sub-sea pipeline wall, the heavier $n$-paraffin fractions precipitate out of solution and form growing orthorhombic crystals. The $n$-paraffin crystals flocculate during crystallization, forming a thin incipient gel layer on the pipeline wall. The interlocking crystal matrix entraps liquid oil within the gel, and serves as a porous media allowing for diffusion of $n$-paraffin components between the bulk oil in the pipeline and the liquid phase of the gel deposit (Singh et al., 2000). Heavy $n$-paraffin components are driven by a solu- 
bility difference from the bulk oil into the gel deposit, while light $n$-paraffin components diffuse from the liquid phase of the gel deposit to the bulk oil. Rigorously, the highest carbon number of the $n$-paraffin components diffusing out of the gel deposit is defined to be the critical carbon number (Singh et al., 2001). Diffusion of wax molecules into the gel deposit leads to subsequent precipitation of high molecular weight $n$-paraffin components within the gel matrix. Hence, the aging process causes an increase in the solid phase fraction of the deposit, resulting in a more rigid gel. The overall wax deposition process can be summarized by the following steps:

(1) Formation of an incipient gel layer on the cold surface, due to rapid precipitation of $n$-paraffin molecules.

(2) Diffusion of $n$-paraffin molecules having a carbon number greater than the critical carbon number to the gel layer from the bulk.

(3) Precipitation of $n$-paraffin molecules at the interface, increasing the gel layer thickness.

(4) Penetration of $n$-paraffin molecules through the liquid phase of the gel matrix.

(5) Precipitation of the diffused $n$-paraffin molecules inside the deposit, increasing the solid fraction of the gel.

(6) Counterdiffusion of $n$-paraffin molecules having a carbon number lower than the critical carbon number (CCN) out of the gel layer.

The counterdiffusion aging process of wax deposits has the effect of shifting the total $n$-paraffin distribution of the gel towards higher carbon numbers. By analyzing the $n$-paraffin composition of a gel deposit over time, one can determine the $\mathrm{CCN}$, which is a manifestation of the relative solubility of $n$-paraffin components in the liquid phase of the gel deposit. As such, the $\mathrm{CCN}$ is a thermodynamic construct independent of the kinetics of $n$-paraffin crystallization. The $\mathrm{CCN}$ concept provides a useful probe for paraffin stability screening in real crude oils, as a numerical CCN value can be quickly and accurately determined without modeling the complex crystallization kinetics occurring in lab-scale wax deposition devices.

The CCN concept has wide applicability in paraffin prevention and remediation. The molecular weight distribution of an aged wax deposit is a strong function of its critical carbon number. Selection of effective chemical wax deposition inhibitors is dependent on crude oil properties and is tailored to the molecular weight distribution of the wax deposit. Hence, the CCN has the potential to be used as an important criterion for inhibitor selection. Various physical and chemical properties of wax deposits are also functions of the critical carbon number. A higher CCN yields a mechanically harder wax with a higher melting point, as well as a lower solubility in typical wax solvents. Therefore, the $\mathrm{CCN}$ can be also used as a selection criterion of solvent packages for wax cleaning in well tubing and downhole treatment operations. Mechanical removal specifications of wax deposits (such as pigging operations) are dependent on deposit hardness. The design of a pig for a soft deposit differs substantially from that of a hard deposit. Optimum operating pressures and flow rates also vary with deposit hardness. Hence, knowledge of the CCN of a waxy crude oil system is beneficial in the design of pigging operations.

The $\mathrm{CCN}$ is dependent on several factors, including temperature, pressure, and oil composition. Singh et al. (2001) have demonstrated using simple model oils that the $\mathrm{CCN}$ increases nearly linearly with gel temperature, and found ex-

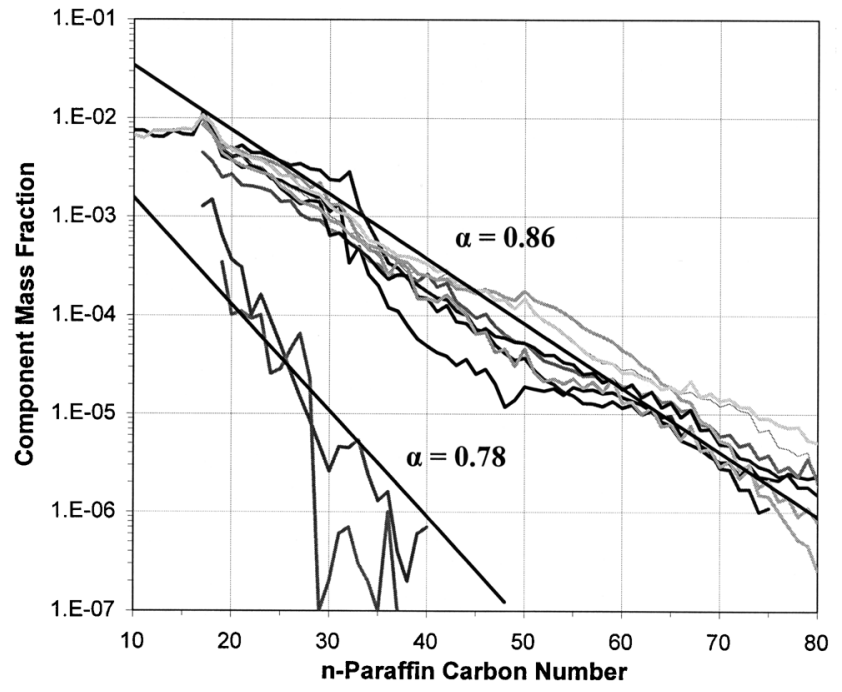

Figure 1. n-Paraffin carbon number distributions (Kaminsky, 2002) of typical crude oils (upper curves) and biodegraded crude oils (lower curves).

Distribution slopes corresponding to recurrence constants used in this work are plotted for reference.

perimental $\mathrm{CCN}$ values in the mid to upper 20s. In this article we describe the influence of $n$-paraffin composition on observed CCNs in wax deposition systems. Model oils consisting of only $n$-alkanes are used in order to gain insight into the aging phenomena, while avoiding complications associated with co-precipitation and analysis of high molecular weight functionalized hydrocarbons. Components such as aromatics, naphthenics, resins, and asphaltenes certainly influence the crystallization kinetics and solid/liquid equilibrium of $n$-paraffin components in crude oil, and will be investigated in a future study.

Singh's depositional studies employed model oils consisting of a commercial paraffin wax dissolved in a mineral oil (Singh et al., 2000) or in a single component solvent such as dodecane (Singh et al., 2001). The carbon number distribution of a simple model oils does not reflect the $n$-paraffin distribution of real crudes, which are known to exhibit decreasing exponential $n$-paraffin distributions through the carbon number range $\sim n-C_{10}$ to $n-\mathrm{C}_{50^{+}}$(Roehner et al., 2002). The carbon number distributions of a variety of real crude oils (Kaminsky, 2002) are shown in Figure 1. The models oils used in the current work attempt to represent realistic $n$-paraffin carbon number distributions, in order to elucidate the relationship between the paraffin composition of a crude oil and its deposition behavior.

\section{Experiment \\ Materials}

Single Component n-alkanes. 18 single component $n$-alkanes of carbon length $n-\mathrm{C}_{9}$ to $n-\mathrm{C}_{26}$ with purities of $98+\%$ (wt.) were purchased from Aldrich and used without further purification.

Paraffin Waxes. Five commercial paraffin waxes were used in formulating the model oils. One paraffin wax was pur- 
Table 1. $n$-Paraffin Carbon Number Distribution (Wt. Fraction) of Commercial Paraffin Waxes, Analyzed using Agilent 6890 Gas Chromatograph

\begin{tabular}{|c|c|c|c|c|c|}
\hline \multirow[b]{2}{*}{$n$-Paraffins } & \multicolumn{5}{|c|}{ Commercial Paraffin Waxes } \\
\hline & $\begin{array}{c}\text { Fluka } \\
\text { m.p. } 44-46^{\circ} \mathrm{C}\end{array}$ & $\begin{array}{c}\text { Aldrich } \\
\text { m.p. } 52-58^{\circ} \mathrm{C}\end{array}$ & $\begin{array}{c}\text { Aldrich } \\
\text { m.p. } 58-62^{\circ} \mathrm{C}\end{array}$ & $\begin{array}{c}\text { Aldrich } \\
\text { m.p. } 65^{\circ} \mathrm{C}\end{array}$ & $\begin{array}{c}\text { Aldrich } \\
\text { m.p. } 73-80^{\circ} \mathrm{C}\end{array}$ \\
\hline$n-C_{17}$ & 0.002 & 0 & 0 & 0 & 0 \\
\hline$n-C_{18}^{1 \prime}$ & 0.018 & 0 & 0 & 0 & 0 \\
\hline$n-C_{19}$ & 0.049 & 0 & 0 & 0 & 0 \\
\hline$n-C_{20}$ & 0.079 & 0.001 & 0.001 & 0 & 0.004 \\
\hline$n-C_{21}^{20}$ & 0.105 & 0.008 & 0.013 & 0 & 0.014 \\
\hline$n-C_{22}^{21}$ & 0.126 & 0.050 & 0.059 & 0.001 & 0.033 \\
\hline$n-C_{23}$ & 0.135 & 0.115 & 0.111 & 0.003 & 0.052 \\
\hline$n-C_{24}$ & 0.133 & 0.165 & 0.155 & 0.006 & 0.064 \\
\hline$n-C_{25}^{24}$ & 0.114 & 0.165 & 0.157 & 0.012 & 0.072 \\
\hline$n-C_{26}^{25}$ & 0.092 & 0.157 & 0.151 & 0.023 & 0.071 \\
\hline$n-C_{27}^{26}$ & 0.063 & 0.111 & 0.112 & 0.042 & 0.070 \\
\hline$n-C_{28}^{21}$ & 0.040 & 0.078 & 0.083 & 0.062 & 0.063 \\
\hline$n-C_{29}$ & 0.021 & 0.051 & 0.056 & 0.086 & 0.059 \\
\hline$n-C_{30}$ & 0.010 & 0.034 & 0.039 & 0.098 & 0.051 \\
\hline$n-C_{31}^{30}$ & 0.005 & 0.023 & 0.025 & 0.108 & 0.049 \\
\hline$n-C_{32}^{31}$ & 0.003 & 0.016 & 0.016 & 0.109 & 0.044 \\
\hline$n-C_{33}^{32}$ & 0.002 & 0.010 & 0.009 & 0.105 & 0.041 \\
\hline$n-C_{34}^{33}$ & 0.001 & 0.007 & 0.006 & 0.090 & 0.037 \\
\hline$n-C_{35}$ & 0.001 & 0.004 & 0.003 & 0.071 & 0.034 \\
\hline$n-C_{36}^{35}$ & 0.001 & 0.002 & 0.002 & 0.051 & 0.030 \\
\hline$n-C_{37}$ & 0 & 0.001 & 0.001 & 0.036 & 0.028 \\
\hline$n-C_{38}$ & 0 & 0 & 0 & 0.027 & 0.024 \\
\hline$n-C_{39}^{38}$ & 0 & 0 & 0 & 0.020 & 0.021 \\
\hline$n-C_{40}^{39}$ & 0 & 0 & 0 & 0.015 & 0.019 \\
\hline$n-C_{41}$ & 0 & 0 & 0 & 0.011 & 0.016 \\
\hline$n-C_{42}$ & 0 & 0 & 0 & 0.008 & 0.017 \\
\hline$n-C_{43}$ & 0 & 0 & 0 & 0.006 & 0.014 \\
\hline$n-C_{44}$ & 0 & 0 & 0 & 0.004 & 0.013 \\
\hline$n-C_{45}$ & 0 & 0 & 0 & 0.003 & 0.012 \\
\hline$n-C_{46}$ & 0 & 0 & 0 & 0.002 & 0.011 \\
\hline$n-C_{47}$ & 0 & 0 & 0 & 0.001 & 0.009 \\
\hline$n-C_{48}$ & 0 & 0 & 0 & 0.001 & 0.007 \\
\hline$n-C_{49}$ & 0 & 0 & 0 & 0.001 & 0.006 \\
\hline$n-C_{50}^{49}$ & 0 & 0 & 0 & 0 & 0.005 \\
\hline$n-C_{51}$ & 0 & 0 & 0 & 0 & 0.004 \\
\hline$n-\mathrm{C}_{52}$ & 0 & 0 & 0 & 0 & 0.003 \\
\hline$n-C_{53}$ & 0 & 0 & 0 & 0 & 0.003 \\
\hline
\end{tabular}

chased from Fluka and had a melting point of $44-46^{\circ} \mathrm{C}$. The remaining paraffin waxes were purchased from Aldrich and had melting points of $52-58^{\circ} \mathrm{C}, 58-62^{\circ} \mathrm{C}, 65^{\circ} \mathrm{C}$, and $73-80^{\circ} \mathrm{C}$. The $n$-paraffin compositions of the waxes were determined using an Agilent 6890 high temperature gas chromatograph with a $0.25 \mu \mathrm{m}$ fused silica stationary phase and an FID detector. The $n$-paraffin carbon number distributions of the waxes are tabulated in Table 1 , and the carbon number distribution of the highest melting wax is shown on a semi-logarithmic scale in Figure 2.

\section{Formulating decreasing exponential distributions of n-paraffins}

Due to the difficulty in obtaining long chain-length single component $n$-paraffins, a novel method was developed to use commercial paraffin waxes to formulate model oils with decreasing exponential carbon number distributions from $n-C_{9}$ to $n-C_{53}$, typical of subsea reservoir crude oils. The approach exploits the high-end "tail" distributions observed in commercial paraffin waxes. As is evident from Figure 2, the highest melting paraffin wax contains a region from $n-C_{46}$ to $n-C_{53}$ with the desired decreasing exponential $n$-paraffin distribution. By combining several paraffin waxes, and employing solid-liquid equilibrium behavior to remove excess compo-

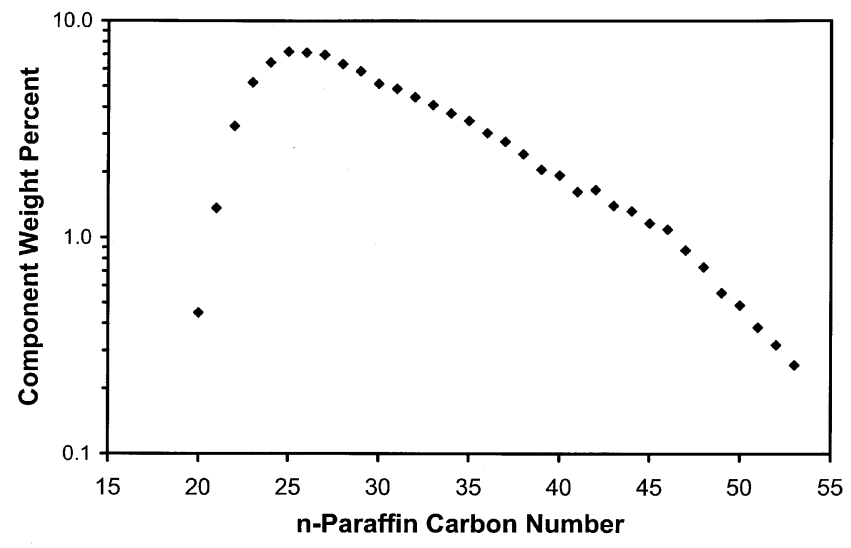

Figure 2. Carbon number distribution of a commercial paraffin wax with a melting point of $73-80^{\circ} \mathrm{C}$. 


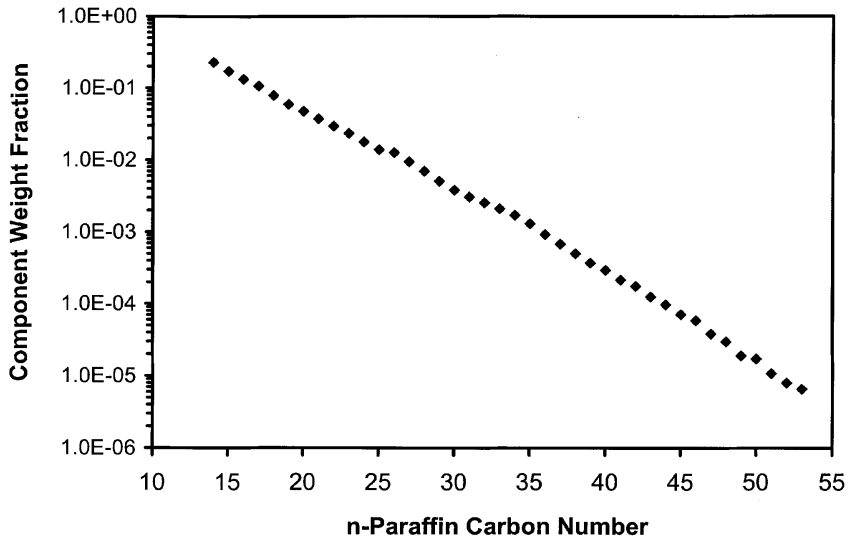

Figure 3. Formulated model oil $n$-paraffin distribution, analyzed by GC.

The fitted recurrence constant $\alpha$ equals 0.78 .

nents, the "decreasing exponential" regime can be extended to carbon numbers in the mid-20s. Single component shortchain $n$-alkanes of carbon number 26 or less comprise the remainder of the model oil. The process of formulating model oils consisting of decreasing exponential $n$-paraffin distributions can be summarized by the following steps:

(1) Combination of calculated proportions of available paraffin waxes yielding approximate decreasing $n$-paraffin fractions from $n-\mathrm{C}_{25}$ to $n-\mathrm{C}_{53^{+}}$.

(2) Addition of single component $n$-paraffins from $n-\mathrm{C}_{9}$ to $\sim n-\mathrm{C}_{26}$ in calculated quantities to fit upper range of decreasing exponential $n$-paraffin distribution.

(3) Precipitation of mid-range $n$-paraffins $\left(n-\mathrm{C}_{30}\right.$ to $\left.n-\mathrm{C}_{45}\right)$ in excess abundance. A cold finger assembly is placed in the model oil solution, such that high carbon number $n$-paraffin components preferentially "deposit out" out of solution. The solution composition is continuously monitored until a linear plot of the weight fraction vs. $n$-paraffin carbon number is achieved on a semi-logarithmic scale, as shown in Figure 3.

The process described can be quite arbitrary, and, as a result, a significant amount of tailoring is required to formulate decreasing exponential $n$-paraffin distributions. The distribution of $n$-paraffin components in the model oils can be characterized in terms of the weight fraction by the following recurrence relationship (Pauly et al., 1998)

$$
x_{C_{n+1}}=\alpha x_{C_{n}}
$$

Model oils containing a single decreasing exponential distribution of $n$-paraffin components can be defined entirely in terms of the recurrence constant $\alpha$ and the respective carbon number range. Using the five available paraffin waxes, two decreasing exponential $n$-paraffin distributions were formulated, corresponding to $\alpha=0.78$ and $\alpha=0.86$. Subsequently, a number of model oils were prepared by varying the lower carbon number limits of the two distributions. For the $\alpha=$ 0.86 distribution, model oils were prepared with lower carbon number limits of $n-\mathrm{C}_{9}, n-\mathrm{C}_{12}, n-\mathrm{C}_{15}$, and $n-\mathrm{C}_{18}$. For the $\alpha=$ 0.78 distribution, model oils were prepared with lower carbon number limits of $n-\mathrm{C}_{14}$ and $n-\mathrm{C}_{18}$. All of the model oils had a common $n$-paraffin upper limit of $n-\mathrm{C}_{53}$, but varied in dis-

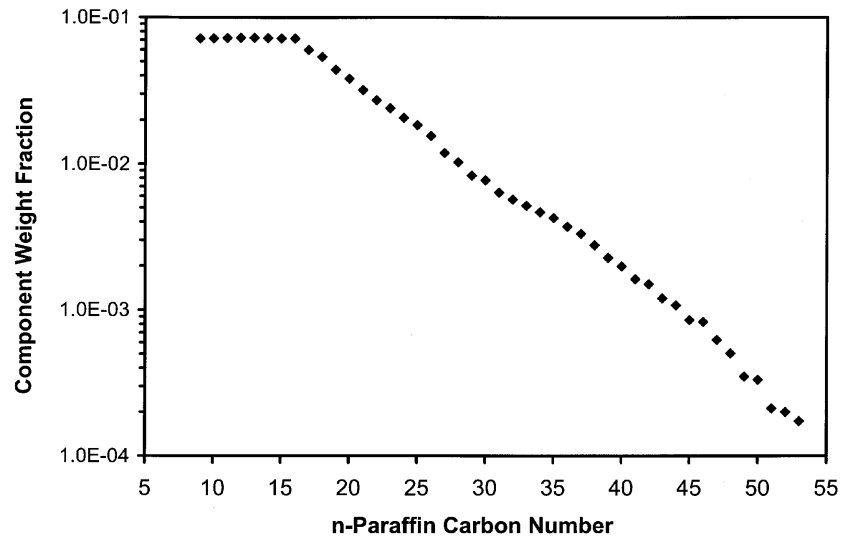

Figure 4. Formulated model oil $n$-paraffin distribution, analyzed by GC.

The $n-C_{16^{+}}$fitted recurrence constant $\alpha$ equals 0.86

tribution shape and lower end composition. Recognizing that crude oil $n$-paraffin distributions vary widely in the low carbon number range, a model oil was formulated with a uniform distribution of $n$-paraffin components in the range $n-\mathrm{C}_{9}$ to $n-\mathrm{C}_{16}$ and an exponential decreasing distribution of $\alpha=$ 0.86 in the range $n-\mathrm{C}_{16}$ to $n-\mathrm{C}_{53}$. A semi-log plot of this composition is illustrated in Figure 4.

\section{Cloud point measurements}

The only significant hydrocarbon components present in the formulated model oils are $n$-paraffins, and, as such, yield clear solutions above the wax appearance temperature (WAT). The WAT represents the solubility limit of the heaviest $n$-paraffin components in an oil solution, and is commonly referred to as the cloud point (Venkatesan et al., 2002). Because $n$-paraffin solutions are clear above the WAT, accurate cloud point measurements of model oils can be performed visually. The error in this method of cloud point determination is estimated to be $\pm 3^{\circ} \mathrm{C}$.

Visual cloud point determination was performed for the formulated model oils by cooling a vial of the model oil in a water bath at $1-2^{\circ} \mathrm{C}$ per min and observing the solution turbidity. Cloud points in the range of $42^{\circ} \mathrm{C}$ to $71^{\circ} \mathrm{C}$ were measured. The observed cloud points decrease with the presence of low carbon number $n$-paraffin components (Figure 5), due to the diluting effects of solvent addition as well as the increased solvent strength associated with low carbon number components. The cloud point of the model oil with a uniform distribution of $n$-paraffin components from $n-\mathrm{C}_{9}$ to $n-\mathrm{C}_{16}$ and a decreasing exponential carbon number distribution from $n-\mathrm{C}_{16}$ to $n-\mathrm{C}_{53}(\alpha=0.86)$ was determined to be $57 \pm 3^{\circ} \mathrm{C}$.

\section{Wax deposition experiments}

A laboratory-scale deposition apparatus called a cold finger was used to simulate wax deposition in crude oil pipelines. The cold finger consists of a temperature controlled steel cylinder immersed in a solution of the model oil. The model oil is contained in a jacketed beaker, such that the temperature of the bulk solution is maintained above the cloud point. A stirrer is placed in the bottom of the vessel to facilitate 


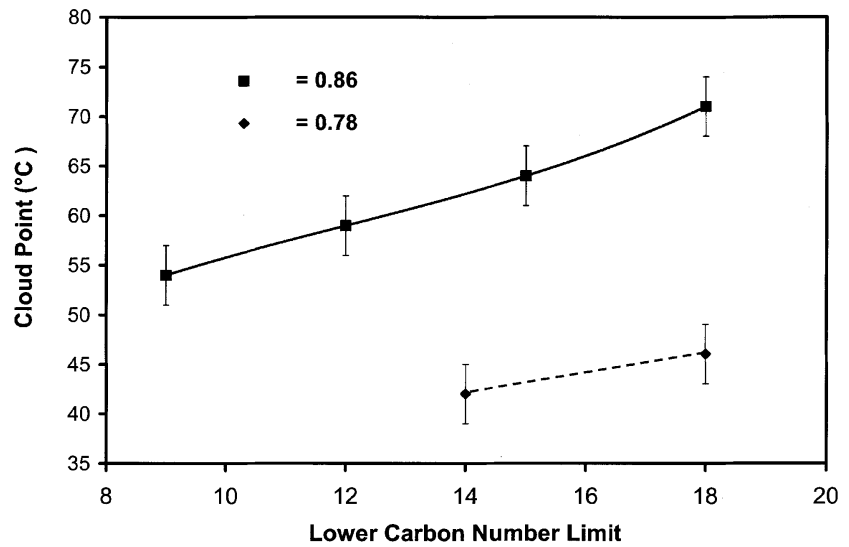

Figure 5. Visually determined cloud points for model oils with decreasing exponential $n$-paraffin distributions from $n-C_{n}$ to $n-C_{53}$, characterized by recurrence constant.

mixing. Ideally, the model oil is circulated through a large volume $(>10 \mathrm{~L})$ reservoir to ensure that depletion of longchain $n$-paraffin components does not occur. However, because a large quantity of the formulated model oils was not available, a reservoir was not used.

In order to maintain consistency in the deposition experiments, a cold finger wall temperature of $15 \pm 1.0^{\circ} \mathrm{C}$ was maintained for all experimental runs. The temperature of the bulk fluid was maintained at $10^{\circ} \mathrm{C}$ above the corresponding cloud point temperature of the model oil, or slightly higher, if necessary, in order to inhibit bulk crystallization. In each cold finger experiment, a deposit sample was recovered from the cold finger at either 7 or $9 \mathrm{~h}$, and analyzed using gas chromatography.

\section{CCN determination}

Incipient wax-oil gel deposits form by precipitated wax crystals entrapping the liquid phase of an oil solution during flocculation. The composition of an incipient gel layer is identical to the bulk oil composition (Singh et al., 2001). After an incipient gel layer is formed, the counterdiffusion aging process begins, manifested by a changing $n$-paraffin composition of the gel deposit. By plotting the aged gel composition along with the composition of the incipient gel, it is readily observed that short $n$-paraffin molecules have diffused out of the gel, and that long $n$-paraffin molecules have diffused into the gel. Hence, the point at which the incipient and aged gel compositions cross defines the critical carbon number for a particular deposition experiment.

Figure 6 shows the incipient gel and aged gel compositions of a model oil composed of $n-\mathrm{C}_{15}$ to $n-\mathrm{C}_{53}$ characterized by a recurrence constant of $\alpha=0.86$. By subtracting the incipient gel composition from the aged gel composition, Figure 7 shows relative diffusion rates of the $n$-paraffin components. In this case, $n$-paraffin components shorter than 24 carbon units have diffused out of the gel, and vice versa. Hence, the critical carbon number is 24 .

The porous structure of the gel matrix facilitates diffusion of $n$-paraffin components between the bulk oil and the liquid

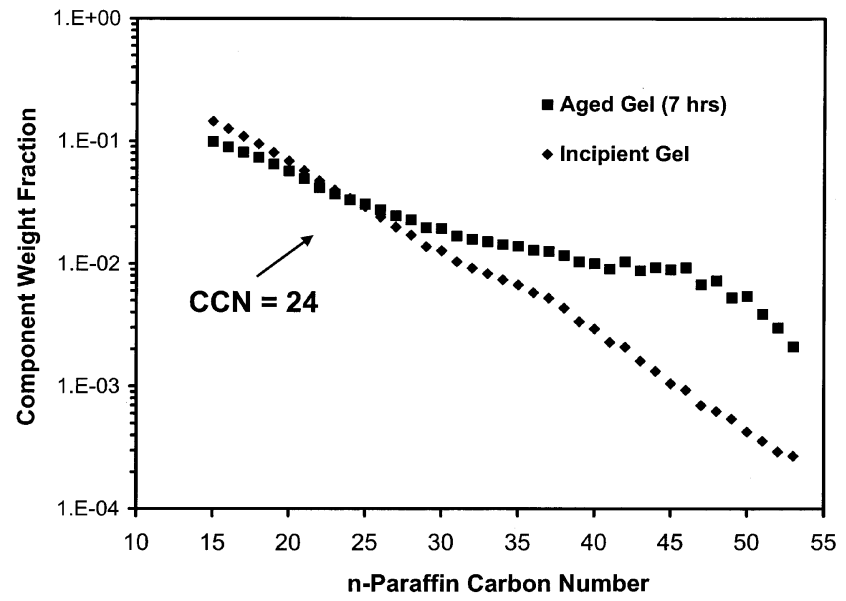

Figure 6. Experimental carbon number distributions of incipient and aged wax-oil gel deposits for model oil containing $n-C_{15}$ to $n-C_{53}, \alpha=0.86$. Cold finger temperature $=15^{\circ} \mathrm{C}$.

phase of the gel deposit, and the diffusion rate of $n$-paraffin components into the gel is highly dependent upon the solid fraction of the incipient gel deposit (Singh et al., 2000). Hence, a deposit with high initial solid fraction will age at a slow rate. For example, the model oil composed of $n-\mathrm{C}_{18}$ to $n-\mathrm{C}_{53}$ characterized by $\alpha=0.86$ shows very little diffusion at $7 \mathrm{~h}$, due to the high initial solid fraction of the incipient gel, although a critical carbon number is evident, as illustrated in Figure 8.

For model oil compositions described by $\alpha=0.86$, it was found that the presence of short $n$-alkanes resulted in an increase in the experimentally observed $\mathrm{CCN}$, ranging from $\mathrm{CCN}=22$ for a lower carbon number limit of 18 to $\mathrm{CCN}=26$ for a lower carbon number limit of 9 . For model oil compositions described by $\alpha=0.78$, the experimentally observed

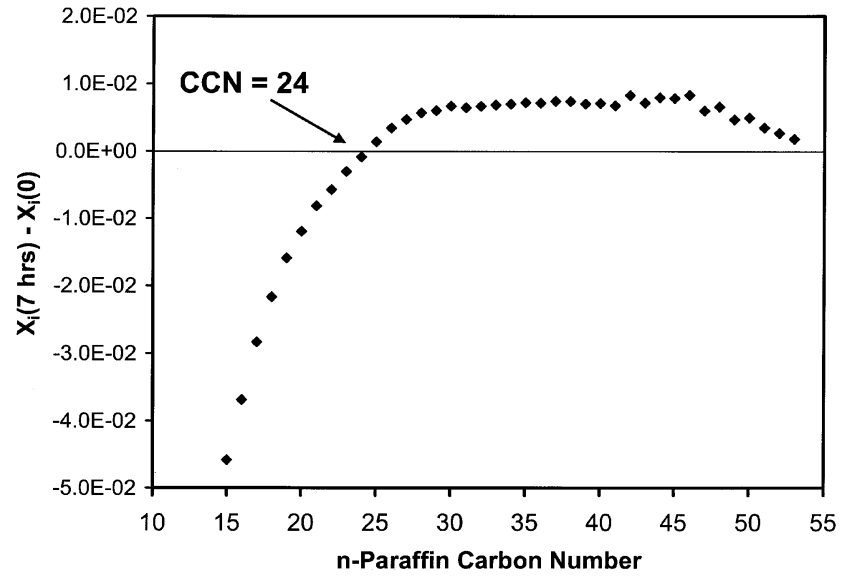

Figure 7. Experimental change in carbon number distribution (weight fraction) of wax-oil gel deposits for model oil containing $n-C_{15}$ to $n-C_{53}, \alpha=0.86$.

Cold finger temperature $=15^{\circ} \mathrm{C}$. 


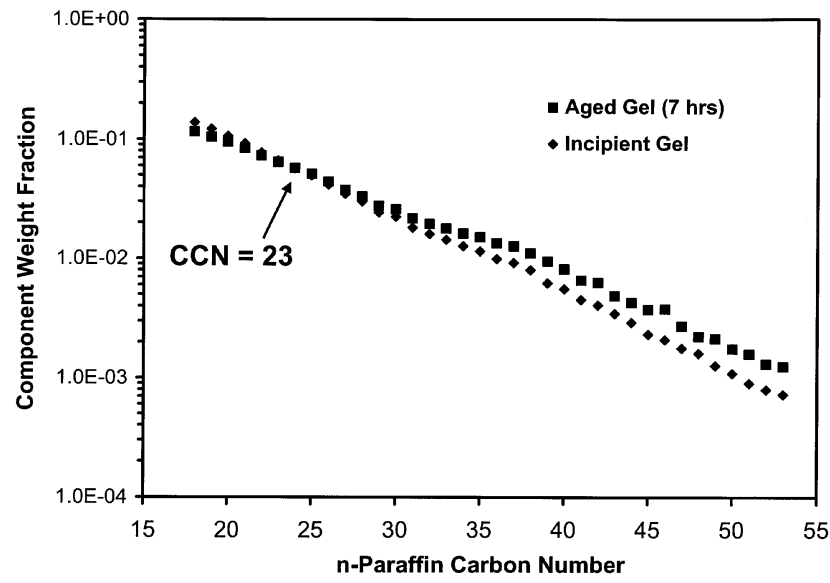

Figure 8. Experimental carbon number distributions of incipient and aged wax-oil gel deposits for model oil containing $n-C_{18}$ to $n-C_{53}, \alpha=0.86$. Cold finger temperature $=15^{\circ} \mathrm{C}$.

$\mathrm{CCN}=17$ for a lower carbon number limit of 14 , and $\mathrm{CCN}=$ 21 for a lower carbon number limit of 18. Experimentally observed critical carbon numbers are plotted vs. the lower limit carbon number of the model oil in Figure 9.

The model oil with a uniform distribution of $n$-paraffin components from $n-C_{9}$ to $n-C_{16}$ (and a subsequent decreasing exponential distribution from $n-\mathrm{C}_{16}$ to $n-\mathrm{C}_{53}$ ) exhibited an experimental CCN value of 24 (Figure 10), lower than the $\mathrm{CCN}$ value of 26 observed for the corresponding model oil with a decreasing exponential distribution along the entire range $n-C_{9}$ to $n-C_{53}$. Deposition behavior, in terms of the critical carbon number and incipient solid-phase fraction, is modeled using solid-liquid equilibrium theory, as described in the following section.

\section{Thermodynamic paraffin deposition modeling}

A number of solid-liquid phase equilibrium models have been developed for paraffin solutions. Holder and Winkler

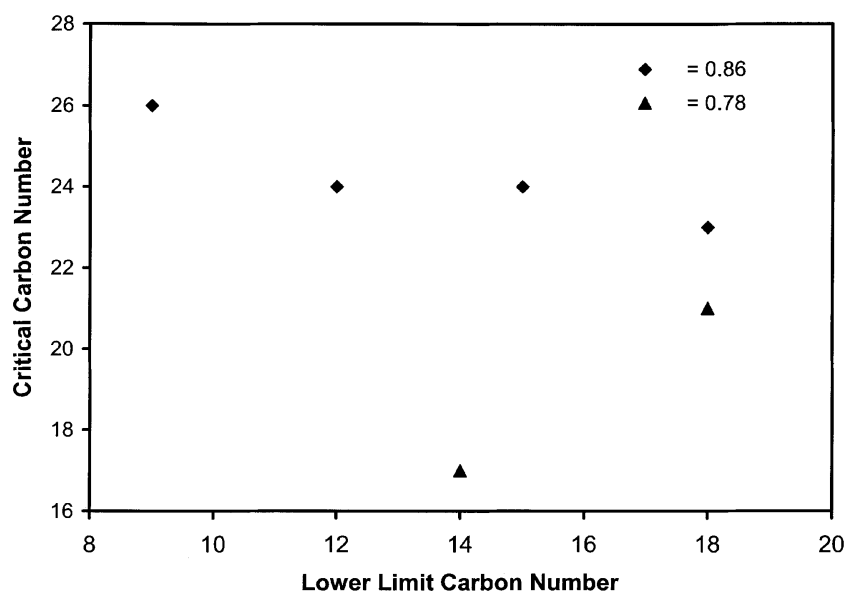

Figure 9. Experimental critical carbon number values for various $n$-paraffin compositions from $n-C_{n}$ to $n-C_{53}$.

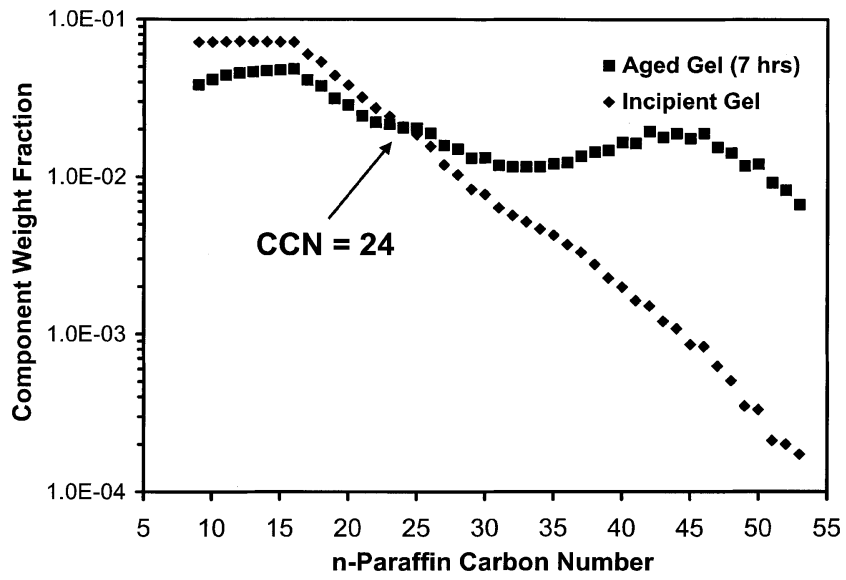

Figure 10. Experimental carbon number distributions of incipient and aged wax-oil gel deposits for model oil with a uniform composition from $n-C_{9}$ to $n-C_{16}$, and subsequently $\alpha=0.86$. Cold finger temperature $=15^{\circ} \mathrm{C}$.

(1965) applied ideal solution theory to binary $n$-alkane mixtures and obtained qualitative agreement with observed cloud point behavior. Won (1986) proposed an alternative to ideal solution theory in which component solid- and liquid-phase activity coefficients are estimated using a modified regular solution theory, and successfully performed three-phase equilibrium calculations for broad hydrocarbon distributions. Pedersen et al. (1991) extended this model by accounting for liquid- and solid-phase heat capacities and by relating paraffin component solubility parameters to the respective number of molecular carbon atoms. Hansen (1988) applied generalized polymer solution theory to account for liquid phase nonidealities in crude oil mixtures. Hansen's model assumes a solid-phase activity coefficient of unity, and includes a subcooling contribution based on surface energy effects to empirically correlate wax appearance temperatures. Ungerer et al. (1995) in studying wax precipitation from high-pressure condensate fluids employed a cubic Peng-Robinson equation of state with classical van der Waals mixing rules to equate liquid- and solid-phase component fugacities. This approach allows for modeling of paraffin crystallization at high pressures.

Coutinho et al. (1995) embarked on a comprehensive investigation of liquid-phase activity coefficient models for alkane mixtures. It was concluded that a free-volume contribution to the liquid-phase activity coefficient is necessary, and is not accurately accounted for in the original Flory-Huggins model, regular solution theory, ideal solution theory, modified UNIFAC, or the original Entropic free-volume model. The Flory free-volume and a modified Entropic free-volume model were deemed to be the most appropriate models.

In accounting for solid-phase interactions, Coutinho (1999) proposed using a predictive local composition model to estimate the excess Gibbs free energy of the solid phase. A modified version of the UNIQUAC model relates the solid-phase activity coefficient to the pair interaction energies between pure $n$-alkane molecules in the orthorhombic phase. Singh et al. (2001) attempted to optimize this model to fit experimental solid-phase compositional data, and employed thermody- 
namic calculations to successfully predict the aging characteristics of simple wax-oil gels. In the present work, Coutinho's model is applied to decreasing exponential $n$-paraffin distributions, and is able to predict $\mathrm{CCN}$ dependencies for representative decreasing exponential $n$-paraffin distributions. The model is described in detail in the following sections.

\section{Solid-liquid equilibrium}

Solid-liquid-phase equilibrium in multicomponent solutions is rigorously expressed as the convergence of component fugacities in the solid and the liquid phase. Solid- and liquid-phase activities can be related to pure component standard fugacities by the fundamental relation (Pauly et al., 1998)

$$
\frac{a_{i}^{S}}{a_{i}^{L}}=\left(\frac{f_{i}^{L_{0}}}{f_{i}^{S_{0}}}\right) \exp \int_{P_{0}}^{P} \frac{\bar{v}_{i}^{L}-\bar{v}_{i}^{S}}{R T} d P
$$

where $f_{i}^{L_{0}}$ and $f_{i}^{S_{0}}$ represent pure component standard state fugacities in the liquid and solid phases, respectively, $\bar{v}_{i}^{L}$ and $\bar{v}_{i}^{S}$ represent the component partial molar volumes in the liquid and solid phases, and $a_{i}^{L}$ and $a_{i}^{S}$ represent the liquidand solid-phase component activities (Prausnitz, 1969). Neglecting pressure dependence and assuming a single solid-solid phase transition between temperature $T$ and pure component melting temperature $T_{m}$, component solid/liquid activity ratios can be related to pure component thermophysical properties by (Coutinho et al., 1999)

$$
\begin{array}{r}
\ln \frac{s_{i} \gamma_{i}^{s}}{x_{i} \gamma_{i}^{L}}=\frac{\Delta h_{m, i}}{R T_{m, i}}\left(\frac{T_{m, i}}{T}-1\right)+\frac{\Delta h_{t r, i}}{R T_{t r, i}}\left(\frac{T_{t r, i}}{T}-1\right) \\
-\frac{\Delta C p_{m, i}}{R}\left(\frac{T_{m, i}}{T}-\ln \frac{T_{m, i}}{T}-1\right) \\
y_{T i}=f_{s} s_{i}+\left(1-f_{s}\right) x_{i} \text { and } \quad \sum_{i} y_{T i}=\sum_{i} s_{i}=\sum_{i} x_{i}=1
\end{array}
$$

where $y_{T i}, x_{i}$, and $s_{i}$ represent the mole fractions of the $i$ th component in the bulk oil, the liquid phase and the solid phase, respectively. $f_{s}$ is the solid-phase fraction. $\gamma_{i}^{s}$ and $\gamma_{i}^{L}$ are the solid- and liquid-phase component activity coefficients, respectively. The solid- and liquid-phase compositions $s_{i}$ and $x_{i}$, as well as the solid-phase fraction $f_{s}$, can be calculated for any temperature provided activity coefficient correlations and thermophysical properties are specified. The following sections describe the activity coefficient correlations used in the calculations. Known thermophysical properties of $n$-paraffin hydrocarbons are tabulated by Singh et al. (2001).

\section{Liquid-phase activity coefficient correlations}

The liquid-phase activity coefficient of an $i$ th component is the product of two contributions: a combinatorial portion accounting for entropic effects of size difference and free volume and a residual portion accounting for energetic interactions among components

$$
\gamma_{i}^{L}=\gamma_{i}^{\text {comb- } f v} \gamma_{i}^{\text {res }}
$$

Saturated aliphatic hydrocarbon mixtures behave nearly athermally, indicating that the component activity coefficients are temperature independent (Singh et al., 2001). Thus, the residual contribution to the liquid-phase activity coefficient can be neglected (that is, $\gamma_{i}^{\text {res }} \approx 1$ ). The Flory freevolume model is used to compute the combinatorial-free volume contribution to the liquid-phase activity coefficient. This term can be expressed as (Coutinho and Stenby, 1996)

$$
\ln \gamma_{i}^{\text {comb- } f v}=\ln \frac{\phi_{i}}{x_{i}}+1-\frac{\phi_{i}}{x_{i}}
$$

In this relation, $x_{i}$ represents the mole fraction of the $i$ th component and $\phi_{i}$ represents the composition fraction of the $i$ th component, defined by

$$
\phi_{i}=\frac{x_{i}\left(V_{i}^{1 / 3}-V_{w i}^{1 / 3}\right)^{3.3}}{\sum_{j} x_{j}\left(V_{j}^{1 / 3}-V_{w j}^{1 / 3}\right)^{3.3}} .
$$

where $V_{i}$ is the $i$ th component molar volume (Elbro et al., 1991) and $V_{w i}$ is the $i$ th component van der Waals volume (Bondi, 1968).

\section{Solid-phase activity coefficient correlations}

Solid-phase activity coefficient correlations are obtained from a modified version of the local composition model UNIQUAC, permitting solid solution equilibrium calculations. The working UNIQUAC relation can be expressed as (Abrams and Prausnitz, 1975)

$$
\begin{aligned}
\frac{g^{E}}{R T}=\sum_{i=1}^{n} s_{i} \ln \left(\frac{\Phi_{i}}{s_{i}}\right) & +\frac{Z}{2} \sum_{i=1}^{n} q_{i} s_{i} \ln \frac{\Theta_{i}}{\Phi_{i}} \\
& -\sum_{i=1}^{n} s_{i} q_{i} \ln \left[\sum_{j=1}^{n} \theta_{j} \exp \left(-\frac{\lambda_{j i}-\lambda_{i i}}{q_{i} R T}\right)\right]
\end{aligned}
$$

with

$$
\begin{array}{r}
\lambda_{i i}=-\frac{2}{Z}\left(\Delta h_{s b l m_{i}}-R T\right), \quad \lambda_{j i}=\lambda_{j j}, \quad \Phi_{i}=\frac{s_{i} r_{i}}{\sum_{j=1}^{n} s_{j} r_{j}}, \\
\text { and } \theta_{i}=\frac{s_{i} q_{i}}{\sum_{j=1}^{n} s_{j} q_{j}}
\end{array}
$$

In this relation, $Z$ is the unit cell coordination number $(Z=6$ for orthorhombic crystals), $\Delta h_{\text {sblm }}$ represents pure $n$-alkane enthalpies of sublimation, $\lambda_{j i}$ is the pair interaction energy between two paraffins in the solid phase, and the structural parameters $r_{i}$ and $q_{i}$ are proportional to the van der Waals volume and area of a "unit of interaction" between two $n$ paraffin molecules (Coutinho, 1999). In order to determine $r_{i}$ and $q_{i}$, a representative number of methylene units for solid-phase interactions must be assumed. To maintain consistency with previous work (Singh et al., 2001), we chose an 
empirical approach defining the interaction unit as being composed of 10 methylene subgroups. Correlations for $r_{i}$ and $q_{i}$ based on this assumption are provided by Coutinho (1999).

From the Gibbs free energy estimation, the logarithm of the $i$ th component activity coefficient is calculated by differentiating the free energy with respect to $n_{i}$

$$
\begin{aligned}
\ln \gamma_{i}^{s}=\left[\frac{\partial\left(n g^{E} / R T\right)}{\partial n_{i}}\right]_{P, T, n_{j}}=1-\frac{\Phi_{i}}{s_{i}}+\ln \left(\frac{\Phi_{i}}{s_{i}}\right) \\
+\frac{Z}{2} q_{i}\left(1-\frac{\theta_{i}}{\Phi_{i}}+\ln \frac{\theta_{i}}{\Phi_{i}}\right)+q_{i}\left(1-\ln \frac{\theta_{i}}{s_{i}}\right) \\
-q_{i} \sum_{j}\left(\frac{q_{j} s_{j} \tau_{i j}}{\sum_{m} s_{m} q_{m} \tau_{m j}}\right)+q_{i} \ln \left(\frac{q_{i}}{\sum_{j} s_{j} q_{j} \tau_{j i}}\right)
\end{aligned}
$$

In this relation, $n$ is the total number of moles of the bulk oil, $n_{i}$ is the number of moles of component $i$ and

$$
\tau_{j i}=\exp \left(-\frac{\lambda_{j i}-\lambda_{i i}}{q_{i} R T}\right) .
$$

\section{Theoretical calculations}

The solid-liquid equilibrium model computes the solidphase fraction $\left(f_{s}\right)$, as well as the liquid- and solid-phase compositions ( $x_{i}$ and $s_{i}$ for each $i$ ) of a paraffin mixture at a specified temperature. Because the solid phase activity coefficient is correlated using a local composition model, multisolid phases are computed. An iterative multiphase flash algorithm as described by Leivobici and Neochil (1995), is used to numerically solve Eqs. 2, 3, 4, and 9 and obtain phase compositions from a given model oil composition. Theoretical solid- and liquid-phase compositions were calculated for a variety of decreasing exponential $n$-paraffin distributions at corresponding temperature conditions of $15^{\circ} \mathrm{C}$ and $25^{\circ} \mathrm{C}$. Figure 11 illustrates the liquid- and solid-phase compositions of a gel obtained from a model oil consisting of a decreasing exponential distribution of components $n-C_{15}$ to $n-C_{52}(\alpha=$ 0.86 ), at $25^{\circ} \mathrm{C}$. A well-defined $\mathrm{CCN}$ value of 23 is evident from the theoretical-phase compositions, and an $18.6 \%$ incipient solid-phase fraction is computed by the thermodynamic model.

Phase composition calculations were performed for model oil compositions described by $\alpha=0.70,0.72,0.74, \ldots 0.96$, and 0.98 . For each recurrence constant $\alpha$, the lower limit carbon number of the input distribution was varied from $n-C_{9}, n-C_{10}$, $\ldots n-C_{18}$. Hence, a large number of permutations of theoretical compositions were calculated, allowing for thorough analysis of CCN dependencies. Phase composition calculations were performed for theoretical paraffin mixtures composed of a uniform distribution of $n$-paraffin components from $n-C_{9}$ to $n-C_{n}$, and a decreasing exponential distribution $(\alpha=0.86)$ of $n$-paraffin components from $n-\mathrm{C}_{n}$ to $n-\mathrm{C}_{52}$, where $n$ was varied from 9 to 16 . Figure 12 illustrates the calculated liquid- and solid-phase compositions for the case where $n=16$. Theoretical $\mathrm{CCN}$ values and incipient solid-phase fractions from all phase calculations are tabulated in the Tables 2-4.

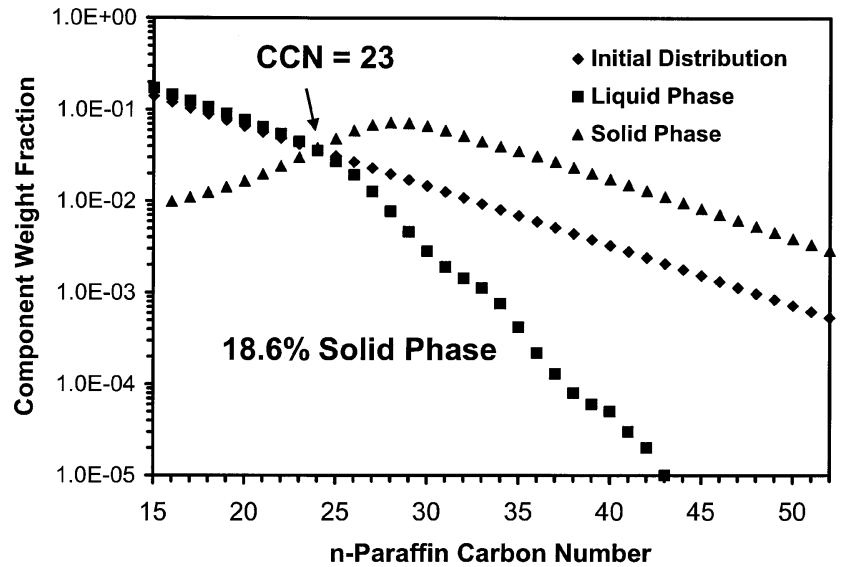

Figure 11. Theoretical solid and liquid phase compositions for $n-C_{15}$ to $n-C_{53}, \alpha=0.86$, at $25^{\circ} \mathrm{C}$.

An analysis of the solid-liquid equilibrium computations indicates that addition of short $n$-paraffin components to a model oil causes an increase in the theoretical CCN and a decrease in the incipient solid fraction of a wax-oil gel. Figures 13 and 14 illustrate theoretical $\mathrm{CCN}$ and incipient solid-phase fraction dependencies on the lower limit carbon number for $n$-paraffin distributions corresponding to $\alpha=0.86$ and $\alpha=0.78$, respectively, at $25^{\circ} \mathrm{C}$. Figure 15 illustrates the theoretical effect of varying the recurrence constant $\alpha$, while keeping a fixed carbon number range from $n-\mathrm{C}_{9}$ to $n-\mathrm{C}_{52}$. The results show an expected decrease in the $\mathrm{CCN}$ with increasing $\alpha$, as well as an increased incipient gel solid fraction. Similar trends are observed for carbon number ranges $n-\mathrm{C}_{10}$ to $n-\mathrm{C}_{52}, n-\mathrm{C}_{11}$ to $n-\mathrm{C}_{52}$, and so on.

Trends in theoretical $\mathrm{CCN}$ and incipient solid fractions were also investigated for $n$-paraffin distributions with uniform lower end component distributions. Figure 16 provides resultant $\mathrm{CCN}$ and solid fraction variations. As the carbon number at which the distribution shifts from "uniform" to "decreasing exponential" varies from 9 to 16 , the theoretical $\mathrm{CCN}$ shows a slight decrease and the incipient solid fraction shows an increase.

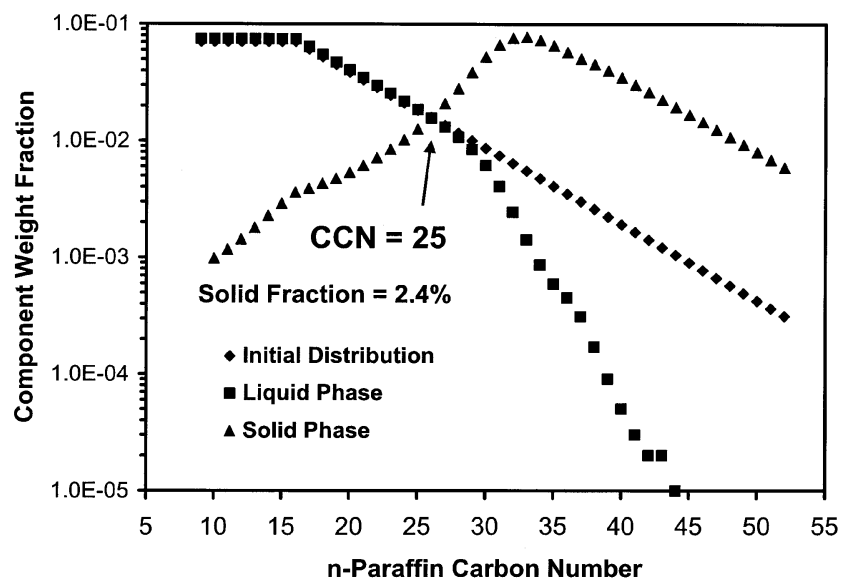

Figure 12. Theoretical solid and liquid phase compositions for a uniform composition from $n-C_{9}$ to $n-C_{16}$, and subsequently $\alpha=0.86$, at $25^{\circ} \mathrm{C}$. 
Table 2. Theoretical CCN Values for Decreasing Exponential $n$-Paraffin Compositions from $n-C_{n}$ to $n-C_{52}$, with Corresponding Recurrence Constant

\begin{tabular}{|c|c|c|c|c|c|c|c|c|c|c|c|c|c|c|c|}
\hline $\begin{array}{l}\text { Lower Limit } \\
\text { Carbon No. }\end{array}$ & 0.7 & 0.72 & 0.74 & 0.76 & 0.78 & 0.8 & 0.82 & 0.84 & 0.86 & 0.88 & 0.9 & 0.92 & 0.94 & 0.96 & 0.98 \\
\hline \multicolumn{16}{|l|}{ at $25^{\circ} \mathrm{C}$} \\
\hline 9 & 29 & 29 & 29 & 29 & 28 & 28 & 28 & 27 & 27 & 26 & 26 & 25 & 25 & 25 & 25 \\
\hline 10 & 29 & 29 & 28 & 28 & 28 & 27 & 27 & 26 & 26 & 26 & 25 & 25 & 25 & 25 & 25 \\
\hline 11 & 28 & 28 & 28 & 28 & 27 & 27 & 26 & 26 & 25 & 25 & 25 & 25 & 25 & 25 & 25 \\
\hline 12 & 28 & 28 & 27 & 27 & 27 & 26 & 26 & 25 & 25 & 25 & 24 & 24 & 24 & 25 & 25 \\
\hline 13 & 27 & 27 & 27 & 26 & 26 & 26 & 25 & 25 & 24 & 24 & 24 & 24 & 24 & 24 & 25 \\
\hline 14 & 27 & 27 & 26 & 26 & 25 & 25 & 24 & 24 & 24 & 24 & 24 & 24 & 24 & 24 & 24 \\
\hline 15 & 27 & 26 & 26 & 25 & 24 & 24 & 24 & 23 & 23 & 23 & 23 & 23 & 24 & 24 & 24 \\
\hline 16 & 26 & 25 & 25 & 24 & 23 & 23 & 23 & 23 & 23 & 23 & 23 & 23 & 23 & 24 & 24 \\
\hline 17 & 25 & 24 & 23 & 23 & 22 & 22 & 22 & 22 & 22 & 22 & 23 & 23 & 23 & 23 & 24 \\
\hline 18 & 22 & 22 & 21 & 21 & 21 & 21 & 22 & 22 & 22 & 22 & 22 & 23 & 23 & 23 & 24 \\
\hline \multicolumn{16}{|l|}{ At $15^{\circ} \mathrm{C}$} \\
\hline 9 & 25 & 25 & 24 & 24 & 24 & 23 & 23 & 23 & 22 & 22 & 22 & 22 & 22 & 22 & 22 \\
\hline 10 & 24 & 24 & 24 & 24 & 23 & 23 & 23 & 22 & 22 & 22 & 22 & 22 & 22 & 22 & 22 \\
\hline 11 & 24 & 24 & 23 & 23 & 23 & 22 & 22 & 22 & 22 & 21 & 21 & 21 & 22 & 22 & 22 \\
\hline 12 & 24 & 23 & 23 & 22 & 22 & 22 & 21 & 21 & 21 & 21 & 21 & 21 & 21 & 22 & 22 \\
\hline 13 & 23 & 22 & 22 & 22 & 21 & 21 & 21 & 21 & 21 & 21 & 21 & 21 & 21 & 21 & 22 \\
\hline 14 & 22 & 22 & 21 & 21 & 21 & 20 & 20 & 20 & 20 & 20 & 20 & 21 & 21 & 21 & 21 \\
\hline 15 & 21 & 20 & 20 & 20 & 20 & 20 & 20 & 20 & 20 & 20 & 20 & 20 & 21 & 21 & 21 \\
\hline 16 & 19 & 19 & 19 & 19 & 19 & 19 & 19 & 19 & 19 & 20 & 20 & 20 & 20 & 21 & 21 \\
\hline 17 & 18 & 18 & 18 & 18 & 19 & 19 & 19 & 19 & 19 & 19 & 20 & 20 & 20 & 21 & 21 \\
\hline 18 & - & - & - & 19 & 19 & 19 & 19 & 19 & 19 & 19 & 20 & 20 & 20 & 21 & 21 \\
\hline
\end{tabular}

\section{Correlating theory and experiment}

The thermodynamic solid-liquid equilibrium model calculates the distribution of $n$-paraffin components between the liquid and solid phases of an incipient gel deposit formed on a cold surface. Theoretical equilibrium compositions provide a critical carbon number to distinguish which paraffin components are favored to diffuse into and out of the liquid phase of the gel deposit in the aging process. Thermodynamics cannot predict mass transfer or internal gel precipitation rates, which are highly dependent on carbon number. Absent accurate kinetic precipitation, gel permeation, and external mass transfer correlations for $n$-paraffin components, the time evolution of deposit compositions, cannot be predicted a priori. Hence, the critical carbon number correlates experimental and theoretical deposit composition data. The largest uncertainty in correlating deposition results with calculated equilibrium compositions lies in representing an appropriate temperature condition of the coldfinger gel deposit. The gel

Table 3. Theoretical Incipient Solid Fractions (in wt. \%) for Decreasing Exponential $\boldsymbol{n}$-Paraffin Composition from $n-C_{n}$ to $n-C_{52}$, with Corresponding Recurrence Constant

\begin{tabular}{|c|c|c|c|c|c|c|c|c|c|c|c|c|c|c|c|}
\hline $\begin{array}{l}\text { Lower Limit } \\
\text { Carbon No. }\end{array}$ & 0.7 & 0.72 & 0.74 & 0.76 & 0.78 & 0.8 & 0.82 & 0.84 & 0.86 & 0.88 & 0.9 & 0.92 & 0.94 & 0.96 & 0.98 \\
\hline \multicolumn{16}{|l|}{ at $25^{\circ} \mathrm{C}$} \\
\hline 9 & 0.00 & 0.00 & 0.00 & 0.00 & 0.02 & 0.08 & 0.31 & 0.97 & 2.40 & 5.30 & 10.10 & 17.30 & 27.10 & 39.10 & 52.30 \\
\hline 10 & 0.00 & 0.00 & 0.00 & 0.00 & 0.04 & 0.15 & 0.53 & 1.50 & 3.40 & 6.90 & 12.50 & 20.30 & 30.50 & 42.50 & 55.50 \\
\hline 11 & 0.00 & 0.00 & 0.00 & 0.02 & 0.07 & 0.29 & 0.88 & 2.20 & 4.80 & 9.10 & 15.30 & 23.80 & 34.30 & 46.40 & 59.00 \\
\hline 12 & 0.00 & 0.00 & 0.00 & 0.03 & 0.16 & 0.54 & 1.50 & 3.50 & 6.80 & 11.80 & 18.80 & 27.80 & 38.60 & 50.50 & 62.70 \\
\hline 13 & 0.00 & 0.00 & 0.02 & 0.08 & 0.33 & 1.00 & 2.60 & 5.30 & 9.50 & 15.40 & 23.20 & 32.60 & 43.50 & 55.20 & 66.80 \\
\hline 14 & 0.00 & 0.00 & 0.04 & 0.21 & 0.74 & 2.00 & 4.40 & 8.10 & 13.30 & 20.10 & 28.50 & 38.30 & 49.10 & 60.30 & 71.20 \\
\hline 15 & 0.00 & 0.02 & 0.13 & 0.59 & 1.80 & 4.00 & 7.50 & 12.30 & 18.60 & 26.20 & 35.10 & 45.00 & 55.50 & 66.00 & 75.90 \\
\hline 16 & 0.01 & 0.10 & 0.56 & 1.90 & 4.30 & 8.00 & 12.90 & 19.00 & 26.20 & 34.40 & 43.50 & 53.10 & 62.90 & 72.30 & 80.90 \\
\hline 17 & 0.90 & 0.80 & 2.80 & 6.00 & 10.50 & 15.90 & 22.20 & 29.20 & 37.00 & 45.30 & 53.90 & 62.60 & 71.10 & 78.90 & 85.70 \\
\hline 18 & 3.38 & 7.60 & 12.80 & 18.40 & 24.60 & 31.00 & 37.80 & 44.70 & 51.70 & 58.80 & 65.80 & 72.70 & 79.00 & 84.70 & 89.60 \\
\hline \multicolumn{16}{|l|}{ at $15^{\circ} \mathrm{C}$} \\
\hline 9 & 0.00 & 0.00 & 0.00 & 0.03 & 0.16 & 0.52 & 1.40 & 3.10 & 6.10 & 10.80 & 17.50 & 26.40 & 37.30 & 49.60 & 62.40 \\
\hline 10 & 0.00 & 0.00 & 0.02 & 0.09 & 0.33 & 0.96 & 2.30 & 4.70 & 8.50 & 13.90 & 21.30 & 30.70 & 41.80 & 54.00 & 66.20 \\
\hline 11 & 0.00 & 0.00 & 0.05 & 0.21 & 0.70 & 1.80 & 3.80 & 7.00 & 11.60 & 18.00 & 26.10 & 35.80 & 46.90 & 58.70 & 70.30 \\
\hline 12 & 0.00 & 0.03 & 0.14 & 0.55 & 1.50 & 3.30 & 6.20 & 10.40 & 16.00 & 23.20 & 31.80 & 41.80 & 52.80 & 64.00 & 74.70 \\
\hline 13 & 0.02 & 0.10 & 0.48 & 1.40 & 3.30 & 6.10 & 10.10 & 15.40 & 22.00 & 29.90 & 39.00 & 49.00 & 59.50 & 69.90 & 79.50 \\
\hline 14 & 0.10 & 0.56 & 1.70 & 3.80 & 7.00 & 11.30 & 16.60 & 23.00 & 30.40 & 38.80 & 47.80 & 57.40 & 67.00 & 76.20 & 84.30 \\
\hline 15 & 1.00 & 2.90 & 6.00 & 10.00 & 15.00 & 20.80 & 27.30 & 34.40 & 42.10 & 50.20 & 58.60 & 67.00 & 75.10 & 82.40 & 88.60 \\
\hline 16 & 8.80 & 13.70 & 19.00 & 24.90 & 30.90 & 37.20 & 43.70 & 50.30 & 56.90 & 63.50 & 70.10 & 76.40 & 82.20 & 87.40 & 91.60 \\
\hline 17 & 32.70 & 37.50 & 42.20 & 46.90 & 51.60 & 56.30 & 60.90 & 65.50 & 70.10 & 74.50 & 78.90 & 83.10 & 87.00 & 90.50 & 93.40 \\
\hline 18 & 50.40 & 53.80 & 57.30 & 60.60 & 64.00 & 67.40 & 70.70 & 74.00 & 77.30 & 80.50 & 83.70 & 86.70 & 89.60 & 92.10 & 94.30 \\
\hline
\end{tabular}


Table 4. Theoretical CCNs and Incipient Solid Fractions for a Uniform Composition of $\boldsymbol{n}$-Paraffin Components from $n-C_{9}$ to $n-C_{n}$, and a Decreasing Exponential $n$-Paraffin Composition from $n-C_{n}$ to $n-C_{52}(\alpha=0.86)$, at $15^{\circ} \mathrm{C}$ and $25^{\circ} \mathrm{C}$

\begin{tabular}{cccccc}
\hline "Bend" & \multicolumn{2}{c}{$15^{\circ} \mathrm{C}$} & & \multicolumn{2}{c}{$25^{\circ} \mathrm{C}$} \\
\cline { 2 - 3 } \cline { 5 - 6 } Carbon No. & CCN & Solid Fraction & & CCN & Solid Fraction \\
\hline 9 & 22 & 0.0613 & & 27 & 0.0242 \\
10 & 22 & 0.064 & & 26 & 0.0253 \\
11 & 22 & 0.0688 & & 26 & 0.0273 \\
12 & 22 & 0.0755 & & 26 & 0.0302 \\
13 & 22 & 0.0845 & & 26 & 0.0341 \\
14 & 22 & 0.0959 & & 26 & 0.0391 \\
15 & 22 & 0.1101 & & 26 & 0.0454 \\
16 & 22 & 0.1276 & 25 & 0.0532 \\
\hline
\end{tabular}

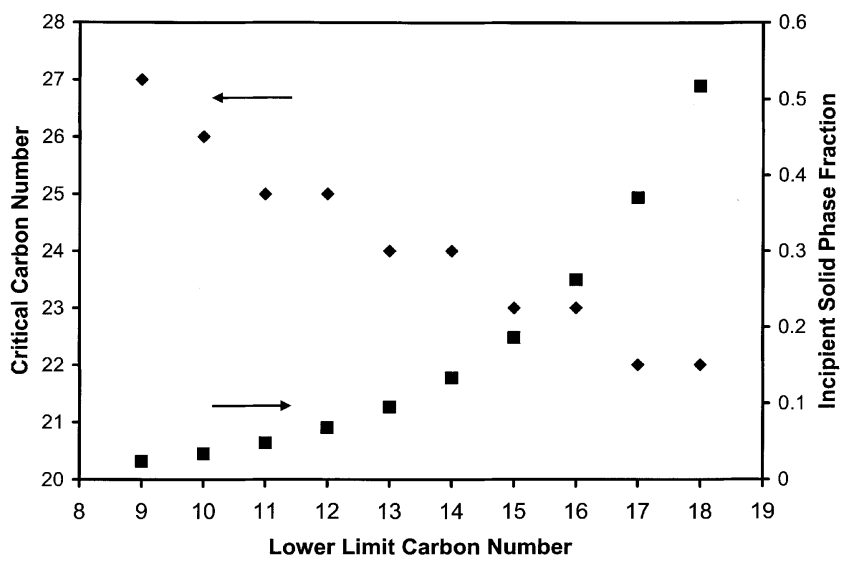

Figure 13. Theoretical $\mathrm{CCN}$ and incipient solid fraction variation with lower limit carbon number for $n-C_{n}$ to $n-C_{52}(\alpha=0.86)$, at $25^{\circ} \mathrm{C}$.

deposit thickness increases with time and does not maintain a static, nor uniform, temperature condition. Singh et al. (2001) in performing thermodynamic equilibrium calculations employed a mean film temperature defined as an average temperature between the coldfinger wall temperature and the

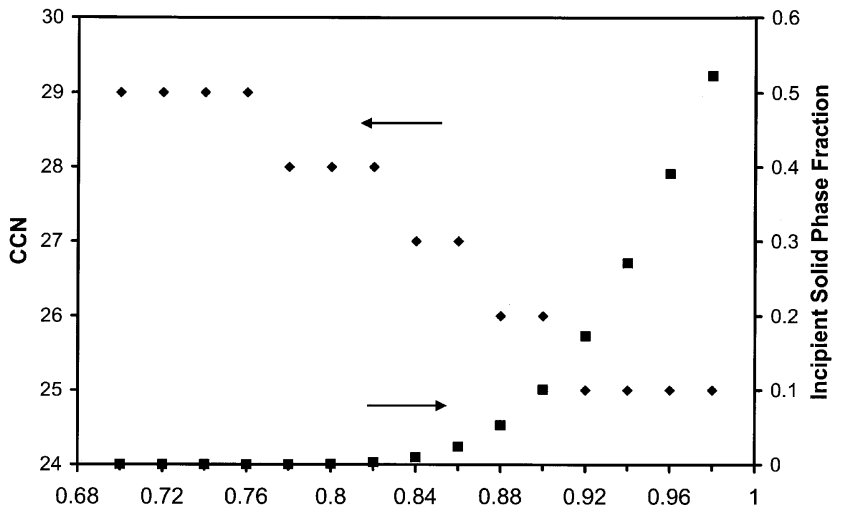

Figure 15. Theoretical $\mathrm{CCN}$ and incipient solid fraction variation with recurrence constant $\alpha$ for $n-C_{9}$ to $n-C_{52}$, at $25^{\circ} \mathrm{C}$.

model oil cloud point. In the present work, phase equilibrium computations at $25^{\circ} \mathrm{C}$ are found to accurately correlate experimental $\mathrm{CCN}$ values obtained at a coldfinger wall temperature of $15^{\circ} \mathrm{C}$, for model oil compositions described by $\alpha=$ 0.86. Both experimental (Figure 9) and theoretical (Figure 13) data indicate an increase in $\mathrm{CCN}$ values as low molecular weight $n$-alkanes are added to the model oil solution. The addition of the paraffin components $n-C_{9}$ to $n-C_{17}$ to the model oil characterized by $n-C_{18}$ to $n-C_{53}(\alpha=0.86)$ results in an increase in the experimentally observed $\mathrm{CCN}$ value from 23 to 26. Equilibrium computations predict a similar increase from 22 to 27. Experimental and theoretical $\mathrm{CCN}$ values show diverging trends for model oil compositions described by $\alpha=$ 0.78. Experimental results (Figure 9) indicate a decrease in the $\mathrm{CCN}$ when the components $n-C_{14}, n-C_{15}, n-C_{16}$, and $n$ $C_{17}$ are included in the model oil solution. The theoretically computed critical carbon numbers for $\alpha=0.78$ indicate an opposing trend (Figure 14). The model oil formulated with a uniform lower end distribution of components from $n-C_{9}$ to $n-C_{16}$ exhibited an experimental CCN value (Figure 10) of 24, and the corresponding thermodynamic calculation (Figure 16) yields a CCN value of 25 .

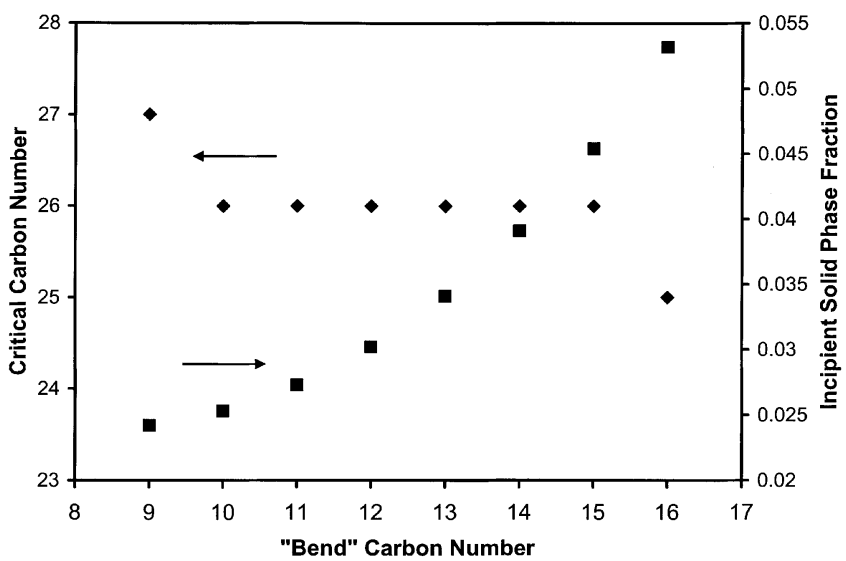

Figure 16. Theoretical $\mathrm{CCN}$ and incipient solid fraction variation with the " Bend"'carbon number for $n-C_{9}$ to $n-C_{52}$, at $25^{\circ} \mathrm{C}$. 


\section{Conclusions}

The applicability of the critical carbon number methodology to describe the aging process of wax-oil gel deposits has been demonstrated for model oils consisting of $n$-paraffin carbon number distributions emulating those observed in real crude oils. Experimentally observed $\mathrm{CCN}$ values were largely expected for model oils containing $n$-paraffin compositions described by $\alpha=0.86$. As light $n$-alkane components are added to a model oil solution in an increasing proportion, carbon numbers in the mid $\mathrm{C}_{20}$ 's gain solubility in the liquid phase, causing an increase in the critical carbon number. Thermodynamic equilibrium calculations generally suggest a decrease in the incipient solid-phase fraction of a wax-oil gel with the addition of light $n$-alkane components in the model oil solution. Unexpected CCN dependencies were observed for the steep $n$-paraffin distributions represented by $\alpha=0.78$. The experimentally observed $\mathrm{CCN}$ was found to decrease sharply when components $n-C_{14}, n-C_{15}, n-C_{16}$, and $n-C_{17}$ were included in the model oil solution described by $\alpha=0.78$. The current theoretical model assuming thermodynamic equilibrium in the gel deposit does not capture this trend.

Experimental deposition results hold several implications in regard to managing paraffin deposition in subsea petroleum pipelines. It is evident that the $C_{19^{+}}$fraction of a crude oil is not a universal measure of paraffin deposition tendency. The critical carbon number establishes an accurate limit to the range of paraffin components that contribute to the deposition and aging process. $\mathrm{CCN}$ values may vary considerably for different crude oil compositions and pipeline conditions. For the prediction of wax deposition rates in field systems, the critical carbon number should be considered alongside bulk oil and wax deposit compositions. A well-designed lab-scale deposition experiment using a real crude sample may be able to quickly and accurately determine the critical carbon number in a field pipeline system, provided temperature conditions are matched. Real pipeline $\mathrm{CCN}$ values can be confirmed by analysis of retrieved wax deposit compositions. Effective chemical wax inhibitors should be targeted to $n$-paraffin components with carbon numbers higher than the CCN value. Inhibitors targeted to $n$-paraffin carbon numbers below the $\mathrm{CCN}$ will be ineffective in slowing the aging process. In any case, an observed $\mathrm{CCN}$ of a crude oil must be considered in a broader context along with the observed deposition kinetics, as well as the shear and temperature gradient conditions within the pipeline.

Laboratory model oil deposition experiments are not directly applicable to pipeline deposition cases. Wax deposits obtained from coldfinger devices form in decaying helical laminar flow fields that cannot be scaled-up to pipeline flow patterns. However, observed trends in $\mathrm{CCN}$ values obtained from model oils are instructive in understanding the thermodynamics underlying the aging process of wax-oil gel deposits.

\section{Acknowledgments}

The authors wish to acknowledge Dr. J. A. P. Coutinho for the use of his solid-liquid phase equilibrium model. Financial support was derived from the University of Michigan Porous Media Industrial Affiliates Program, including Baker Petrolite, ChevronTexaco, ConocoPhillips, Halliburton, PDVSA, Schlumberger, Shell Oil, and Total
Fina Elf. Additional funding was provided by NSF grant CTS9905142.

\section{Notation}

$a=$ activity recurrence constant

$f=$ fugacity

$f_{s}=$ solid fraction

$g=$ Gibbs free energy $(\mathrm{kJ} / \mathrm{mol})$

$h=$ enthalpy $(\mathrm{kJ} / \mathrm{mol})$

$R=$ ideal gas constant

$T=$ temperature $(\mathrm{K})$

$V=$ molar volume $\left(\mathrm{cm}^{3} / \mathrm{mol}\right)$

$q=$ surface area parameter (UNIQUAC)

$r=$ volume parameter (UNIQUAC)

$s=$ solid-phase molar fraction

$\bar{v}=$ partial molar volume

$x=$ liquid phase molar fraction

$Z=$ coordination number

$\gamma=$ activity coefficient

$\theta=$ area fraction

$\lambda=$ interaction parameter

$\phi=$ volume fraction

\section{Subscripts}

$i=$ component

$n=n$-paraffin carbon number

$m=$ melting

$\operatorname{tr}=$ solid-solid transition

sblm $=$ sublimation

$w=$ van der Waals

\section{Superscripts}

$$
\begin{aligned}
\mathrm{comb} & =\text { combinatorial } \\
\mathrm{res} & =\text { residual } \\
f & =\text { free volume } \\
E & =\text { excess } \\
L & =\text { liquid } \\
s & =\text { solid }
\end{aligned}
$$

\section{Literature Cited}

Abrams, D. S., and J. M. Prausnitz, "Statistical Thermodynamics of Liquid Mixtures: A New Expression for the Excess Gibb's Free Energy of Partly or Completely Miscible Systems," AIChE J., 21, 116 (1975).

Bondi, A., Physical Properties of Molecular Crystals, Liquids, and Glasses, Wiley, New York (1968).

Coutinho, J. A. P., J. A. Lopes da Silva, A. Ferreira, M. R. Soares, and J. L. Daridon, "Evidence for the Aging of Wax Deposits in Crude Oils by Ostwald Ripening," Pet. Sci. Tech., 21, 381 (2003).

Coutinho, J., S. I. Andersen, and E. H. Stenby, "Evaluation of Activity Coefficient Models in Prediction of Alkane Solid-Liquid Equilibria," Fluid Phase Equil., 103, 23 (1995).

Coutinho, J. A. P., and E. H. Stenby, "Predictive Local Composition Models for Solid/Liquid Equilibrium in n-Alkane Systems: Wilson Equation for Multicomponent Systems," Ind. Eng. Chem. Res., 35, 918 (1996).

Coutinho, J. A. P., "Predictive Local Composition Models: NRTL and UNIQUAC and their Application to Model Solid-Liquid Equilibrium of $n$-alkanes," Fluid Phase Equil., 159, 447 (1999).

Dirand, M., V. Chevallier, E. Provost, M. Bouroukba, and D. Petitjean, "Multicomponent Paraffin Waxes and Petroleum Solid Deposits: Structural and Thermodynamic State," Fuel, 77, 1253 (1998).

"DOE, University of Tulsa Embark on Wax Deposition Study," Oil \& Gas J., 99, 56 (2001).

Elbro, H. S., A. Fredenslund, and P. Rasmussen, "Group Contribution Method for the Prediction of Liquid Densities as a Function of Temperature for Solvents, Oligomers, and Polymers," Ind. Eng. Chem. Res., 30, 2576 (1991).

Hansen, J. H., "A Thermodynamic Model for Predicting Wax Formation in Crude Oils," AIChE J., 38, 1937 (1988). 
Hansen, A. B., E. Larsen, W. B. Pedersen, A. B. Nielsen, and H. P. Rønningsen, "Wax Precipitation from North Sea Crude Oils. 3. Precipitation and Dissolution of Wax Studied by Differential Scanning Calorimetry," Energy \& Fuels, 5, 914 (1991).

Holder, G. A., and J. Winkler, "Wax Crystallization from Distillate Fuels, Part I. Cloud and Pour Phenomena Exhibited by Solutions of Binary $n$-Paraffin Mixtures," J. Inst. Petrol., 51, 228 (1965).

Kaminsky, R. D., "Wax as a Flow Assurance Issue: Past and Future," AIChE Meeting, New Orleans, LA (2002).

Leivobici, C. F., and J. Neoschil, "Solution of Rachford-Rice Equations for Multi-Phase Systems," Fluid Phase Equil., 112, 217 (1995).

Pauly, J., C. Dauphin, and J. L. Daridon, "Liquid-Solid Equilibria in a Decane Plus Multi-Paraffins System," Fluid Phase Equil., 149, 191 (1998).

Pedersen, K. S., P. Schovborg, and H. P. Rønningsen, "Wax Precipitation from North Sea Crude Oils. 4. Thermodynamic Modeling," Energy and Fuels, 5, 924 (1991).

Prausnitz, J. M., Molecular Thermodynamics of Fluid Phase Equilibria, Prentice-Hall, Englewood Cliffs, NJ (1969).

Roehner, R. M., J. V. Fletcher, and F. V. Hanson, "Comparative Compositional Study of Crude Oil Solids from the Trans Alaska Pipeline System Using High-Temperature Gas Chromatography," Energy and Fuels, 16, 211 (2002).
Singh, P., A. Youyen, and H. S. Fogler, "Existence of a Critical Carbon Number in the Aging of a Wax-Oil Gel," AIChE J., 47, 2111 (2001).

Singh, P., R. Venkatesan, H. S. Fogler, and N. Nagarajan, "Formation and Aging of Incipient Thin Film Wax-Oil Gels," AIChE J., 46, 1059 (2000).

Singh, P., H. S. Fogler, and N. Nagarajan, "Prediction of the Wax Content of the Incipient Wax-Oil Gel in a Flow Loop: An Application of the Controlled-Stress Rheometer," J. Rheol., 46, 1437 (1999).

Ungerer, P., B. Faissat, C. Leibovici, H. Zhou, E. Behar, G. Moracchini, and J. P. Courcy, "High Pressure-High Temperature Reservoir Fluids: Investigation of Synthetic Condensate Gases Containing a Solid Hydrocarbon.” Fluid Phase Equil., 111, 287 (1995).

Venkatesan, R., P. Singh, and H. S. Fogler, "Delineating the Pour Point and Gelation Temperature of Waxy Crude Oils," SPE J., 7, 349 (2002).

Won, K. W., "Thermodynamics for Solid-Liquid Equilibria: Wax Phase Formation from Heavy Hydrocarbon Mixtures," Fluid Phase Equil., 30, 265 (1986).

Manuscript received Dec. 12, 2002, and revision received Aug. 5, 2003. 